\title{
Reducing Reforestation Costs in Lebanon: Adaptive Field Trials
}

\author{
Garabet (Garo) Haroutunian ${ }^{1}$, David C. Chojnacky ${ }^{2, *}$, Richard El Riachy ${ }^{1}$ and \\ Cindy C. Chojnacky ${ }^{3}$ \\ 1 United Nations Development Programme, Bekaa Office, Ghazzah Center, Bloc B, 2nd floor, Chtaura, \\ main road, Bekaa 1802, Lebanon; garo.haroutunian@undp.org (G.H.); richard.el-riachy@undp.org (R.E.R.) \\ 2 Virginia Polytechnic Institute and State University, (located off-campus) 827 Countryside Blvd, Hailey, \\ ID 83333, USA \\ 3 Independent Writer/Researcher, 827 Countryside Blvd, Hailey, ID 83333, USA; cindychoj@gmail.com \\ * Correspondence: dchojnac@vt.edu; Tel.: +1-703-343-3288
}

Academic Editors: Thomas J. Straka and Timothy A. Martin

Received: 3 February 2017; Accepted: 6 May 2017; Published: 17 May 2017

\begin{abstract}
Lebanon's Ministry of Environment initiated a project in 2009 to determine low-cost reforestation techniques for stone pine (Pinus pinea) and Lebanon cedar (Cedrus libani) for large-scale land rehabilitation activities in the arid Middle East. Irrigation (several techniques vs. no water), planting (8- to 18-month-old seedlings), seeding, and soil preparation methods were evaluated in three sets of adaptive management field trials. The aim was to reduce reforestation costs while still achieving sufficient regeneration. A key result for management was that non-irrigated seed planting of stone pine and possibly of Lebanon cedar showed promise for cost-effective reforestation and could be competitive with seedlings, given correct seed source and planting conditions. Stone pine seeds collected from nearby mother trees and planted without irrigation on sandy soil showed 35\% survival for $<600$ USD/ha; seedlings planted without irrigation cost about 2500 USD/ha and achieved 50-70\% survival (costs based on 800 seedlings/ha). Water supplements increased establishment costs over 2 years without concomitant improvements to survival. Future studies should evaluate how soil texture and soil preparation interact with other factors to affect seed germination and survival for each species.
\end{abstract}

Keywords: dryland forestry; seedlings; seeding; Cedrus libani; Pinus pinea; nursery techniques

\section{Introduction}

Historical records and pollen studies indicate Lebanon was once covered with great forests of conifers [1]. Prehistoric forests may have covered more than 70\% of the country [2], but today forests are estimated at only $13 \%$, and other woodlands at $10 \%$, of the land area in Lebanon [3]. As early as 7700 BCE, Neolithic people may have harvested Lebanon cedar (Cedar of Lebanon, Cedrus libani; Figure 1a) [4], with subsequent exploitation by Phoenicians, Assyrians, Babylonians, kings of Israel, Romans, and the Turkish Ottoman Empire [5]. In the 7th century CE, people began to occupy the high mountains, cutting forests and grazing livestock that depleted seedlings. Since then, forests have been cut for firewood and railroads; reduced by agriculture, lime furnaces, and lime quarries; and attacked by insects [1]. The Lebanese Civil War (1975-1990) prompted urban migration to the mountains, causing further deforestation and land degradation [2]. 


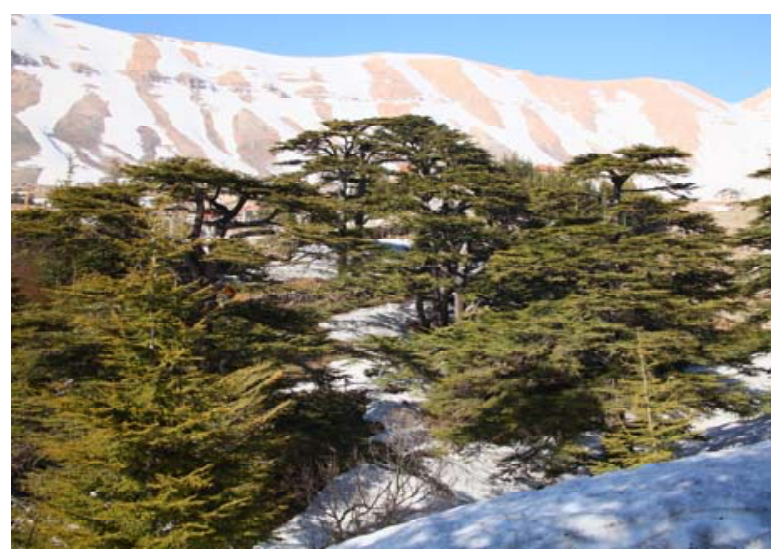

(a)

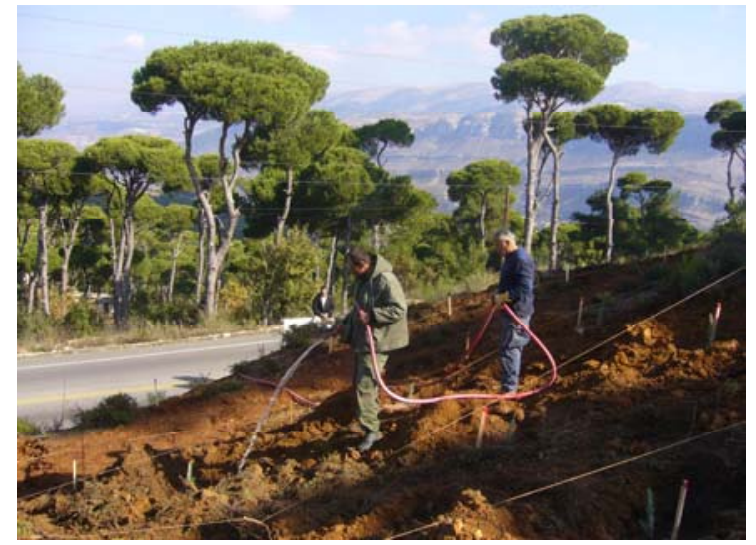

(b)

Figure 1. (a) One of the remaining old-growth Lebanon cedar groves on the west side of the ridge just below Mount Lebanon; (b) Mature stone pines at this study's Bkassin trial site. Foreground shows conventional irrigation of seedlings in mechanically-prepared soil.

Lebanon cedar is key to the identity of Lebanon, and its restoration is the focus of government, non-governmental organization (NGO), and donor efforts in reforestation (seeding or planting young trees in an area where there used to be a forest). It only exists in 12 stands covering about 2000 hectares [6] and is on the International Union for Conservation of Nature Red List of Threatened Species [7]. However, important reforestation work in Lebanon has also aimed to establish stone pine (Pinus pinea; Figure 1b) plantations at low elevations. Experts dispute whether stone pine is native to Lebanon, but there is evidence it was introduced as early as the 12th century CE [8]. Stone pine nuts, a staple in Middle Eastern cuisine, are an important crop [9]. Private owners began to reforest with stone pine in the 1930s, and the Lebanese government undertook ambitious reforestation of stone pine from 1960 to 1975 but war curtailed those efforts [9].

The 21st century brought renewed reforestation interest. The Ministry of Environment's (MoE) National Reforestation Plan aims to restore forest cover to $20 \%$ over 30 years. To build capacity, MoE initiated the five-year "Safeguarding and Restoring Lebanon's Woodland Resources Project" (SRLWRP) with the United Nations Development Programme (UNDP) and the Global Environment Facility (GEF). SRLWRP included nursery improvements, reforestation contracts with municipalities, and the field trials discussed in this paper. As in many international development projects, the trials were designed by SRLWRP not to conduct scientific research, but to solve practical problems-specifically, to evaluate low-cost reforestation methods and their suitability to Lebanese conditions.

Very little literature published in English specifically focuses on Lebanese reforestation, but some critical issues have been studied in other dry regions of the world. Most previous work has emphasized seedling planting. Improved seedling survival has been tested through nursery seed sowing time and depth [10], drought preconditioning of seedlings [11,12], water supplements [13], and use of appropriate containers $[14,15]$.

Direct seeding costs less than outplanting seedlings, but is often avoided in dryland areas because of seed vulnerability to drought, wind, and predation [13]. Most direct seeding in the United States today is limited to wildfire-decimated tracts, but the technique has been used to regenerate deforested areas in the southern part of that country with southern pines [16]. Lebanon cedar was restored to bare karstic lands in Turkey using large-scale broadcast seeding that mimicked natural processes [11,17]. High germination rates have been reported for stone pine [18], and Takos and Merou [19] achieved up to $80 \%$ germination for Lebanon cedar seeds after proper storage and treatment. Use of site-adapted seed is critical for success [13].

Water availability, a limiting factor in seedling establishment, may become even more important with climate change effects [20]. Choices of techniques for efficient water use and water 
supplementation systems are affected by factors such as soil conditions, species planted, and available funds and equipment [13]. Adding water-absorbent polymers improved seedling survival of stone pine in Spain [21]. However, Boydak [17] seeded Lebanon cedar in Turkey successfully without irrigation.

Needed site preparation is site-specific [13]. Direct-seeded Lebanon cedar required no soil preparation in karstic lands in Turkey where soil depths were shallow to medium with bedrock cracks, but where soil was deeper and seedlings were planted, deep soil tillage was essential [11]. Soil texture can also affect success: Bravo-Oviedo and Montero [22] found stone pine in southwest Spain did better in sites with higher sand content and less silt and clay. In Turkey, Lebanon cedar is found mainly on calcareous, well-drained loamy soils [11,17]; Semerci [23] found seedlings survived well after 5 years on silt and clay soils, but observed decreased survival on one site with high clay content.

In our study, we analyzed data from the already-completed 2011-2014 SRLWRP field trials of reforestation techniques for stone pine and Lebanon cedar. For reasons detailed below, trials with Lebanon cedar were limited, but we include them here because the species is so important to Lebanon and is the impetus for many reforestation efforts. SRLWRP had used various combinations of nursery-grown seedlings, seed planting, and seed sowing, with the goal of finding low-cost effective reforestation techniques for large-scale land rehabilitation activities in the arid Middle East. The focus was on improving reforestation techniques through an iterative adaptive management process, rather than scientific research, and the trials were not designed for statistical evaluation. However, statistical analysis and additional examination of project data by our study's second author, who had been contracted after field studies were completed to produce a final UNDP report, revealed interesting findings on seed and seedling survival that merited sharing with the wider scientific community in a format outside the project report. These post-project findings are the subject of this paper, which attempts to condense and highlight this portion of the UNDP report. Complete details on the broader SRLWRP reforestation project are provided in the full report, available online [24].

\section{Materials and Methods}

\subsection{Field Trial Overview}

The SRLWRP field project design consisted of three successive sets of field trials implemented on seven sites (Figure 2); each set included two summer growing seasons and used preliminary results from the previous set to select factors to be examined. Methods of irrigation (several techniques vs. no water), planting (8- to 18-month-old seedlings), seeding, and soil preparation were evaluated for their ability to minimize reforestation costs while producing acceptable seedling survival (Table 1).

Water is costly, difficult to obtain, and a limiting factor in reforestation in this arid region, so a primary objective of the Set I trials was to compare effects of irrigation methods (two slow-release water methods, hose irrigation, and no irrigation) on P. pinea seedlings. Because conventional (hose) and more costly novel (slow-release) irrigation produced similar results in Set I, slow-release methods were eliminated in Set II. Set II trials compared hose irrigation and no irrigation; two seedling ages from both C. libani and P. pinea, with a wider age range than in Set I; and planted and sown seeds. (No seed sowing was done for Set I because a late project start missed the appropriate season.) Set III trials with C. libani and P. pinea focused on reducing reforestation costs further by planting only non-irrigated seeds, in imitation of nature. Set III also compared hand and mechanical soil preparation. These were not compared in Sets I and II, where the least expensive method of preparation available was used. 


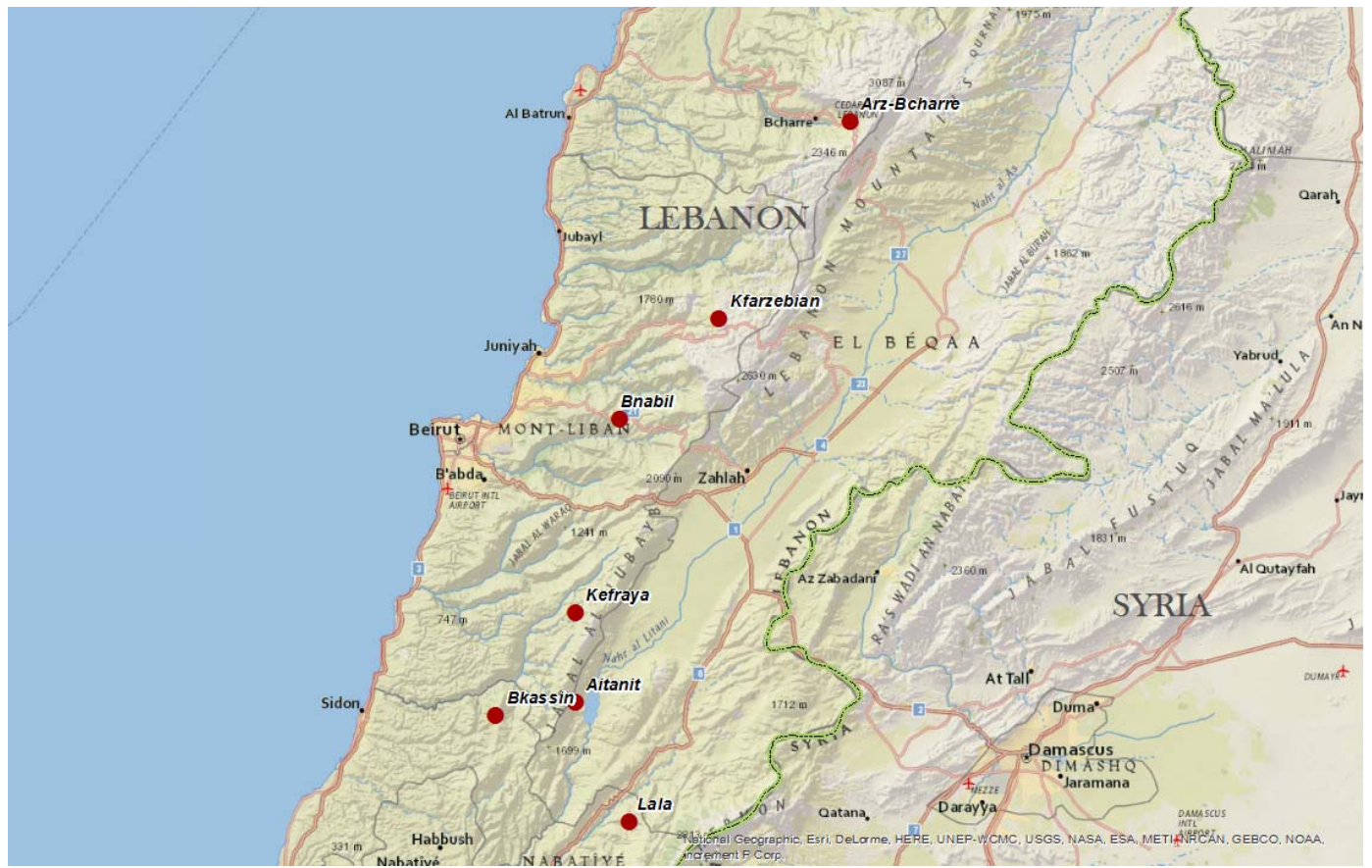

Figure 2. Field trial sites.

\subsection{Field Trial Sites}

Sites were selected for diverse growing conditions and elevations, proximity to roads, and ownership that ensured project continuity (government, or in one case, a monastery). Stone pine and Lebanon cedar were planted at elevations of 998-1147 m and 1968-2012 m, respectively. Treatments were arranged on sites for convenience of keeping track of trees for repeated measurements. Seedlings and seeds were generally planted in rows, across slope if possible, and seeds sown in rectangular areas; but data recorded included no layout information. Thus, no within-site effects were considered.

\subsection{Field Methods}

\subsubsection{Set I Trials}

In Set I, stone pine seedlings were planted in the spring at three sites-Kefraya, Aitanit, and Lala-to compare four irrigation methods and two seedling ages (8-10 mo and $12 \mathrm{mo}$ ) (Table 1). Fifty plants for each of the 8 irrigation-age treatment combinations resulted in 400 seedlings on the half-hectare site. This density was equivalent to the project's target reforestation guideline from the Lebanon Ministry of Environment of 800 seedlings per ha. Eight rows ( 1 for each treatment combination) of 50 seedlings each were generally planted across slope. Seedlings, grown in plastic bags (10 cm diameter, $20 \mathrm{~cm}$ long), were planted in April due to project initiation logistics. (Sets II and III were planted just before winter rains, which is preferable for seed growth or seedling establishment.) 
Table 1. Background information for Lebanon planting trials of stone pine (Pinus pinea) and Lebanon cedar (Cedrus libani) at 7 sites: (A) site characteristics; (B) planting and treatments.

\begin{tabular}{|c|c|c|c|c|c|c|c|c|}
\hline \multicolumn{9}{|l|}{ (A) } \\
\hline Set & Site & & Elevation $(\mathrm{m})$ & Geographic Coordinates & \multicolumn{2}{|c|}{ Soil Description (Texture; Depth; Rock) } & $\begin{array}{c}\text { Average Annual } \\
\text { Precipitation (mm) }\end{array}$ & $\begin{array}{l}\text { Temperature } \\
\text { Means January } \\
\text { \& August }\left({ }^{\circ} \mathrm{C}\right)\end{array}$ \\
\hline I & Kefraya & & 998 & $33^{\circ} 40^{\prime} 38.02^{\prime \prime} \mathrm{N}, 35^{\circ} 44^{\prime} 36.90^{\prime \prime} \mathrm{E}$ & $38 \%$ sand, $32 \%$ clay, & $0 \%$ silt; deep; $10 \%$ rock & 850 & $2.0,33.4$ \\
\hline I & Aitanit & & 1147 & $33^{\circ} 34^{\prime} 20.34^{\prime \prime}$ N, $35^{\circ} 40^{\prime} 18.64^{\prime \prime} \mathrm{E}$ & $56 \%$ silt, $34 \%$ clay, $10^{\circ}$ & sand; medium; $40 \%$ rock & 1016 & $1.9,30.7$ \\
\hline I & Lala & & 1035 & $33^{\circ} 35^{\prime} 57.49^{\prime \prime} \mathrm{N}, 35^{\circ} 44^{\prime} 55.31^{\prime \prime} \mathrm{E}$ & $54 \%$ silt, $36 \%$ clay, $10^{\circ}$ & sand; shallow; $33 \%$ rock & 850 & $-0.4,28.6$ \\
\hline II & Bkassin & & 1032 & $33^{\circ} 33^{\prime} 23.53^{\prime \prime} \mathrm{N}, 35^{\circ} 33^{\prime} 37.40^{\prime \prime} \mathrm{E}$ & $76 \%$ sand, $16 \%$ clay & \% silt, deep; $10 \%$ rock & 1250 & $-0.5,31.9$ \\
\hline II & Arz-Bcharre & & 1968 & $34^{\circ} 14^{\prime} 51.30^{\prime \prime} \mathrm{N}, 36^{\circ} 03^{\prime} 27.30^{\prime \prime} \mathrm{E}$ & $50 \%$ clay, $36 \%$ silt, 1 . & \% sand; deep; $20 \%$ rock & 970 & $\begin{array}{l}-0.3,01.9 \\
-10.6,27.2\end{array}$ \\
\hline III & Bnabil & & 1076 & $33^{\circ} 54^{\prime} 07.39^{\prime \prime} \mathrm{N}, 35^{\circ} 44^{\prime} 05.19^{\prime \prime} \mathrm{E}$ & $70 \%$ sand, $20 \%$ clay & $10 \%$ silt; deep; $5 \%$ rock & 1270 & $-1.0,32.9$ \\
\hline III & Kfarzebian & & 2012 & $34^{\circ} 01^{\prime} 09.30^{\prime \prime} \mathrm{N}, 35^{\circ} 52^{\prime} 25.89^{\prime \prime} \mathrm{E}$ & $43 \%$ clay, $36 \%$ silt, 2 & o sand; deep; $40 \%$ rock & 1400 & $-6.5,27.2$ \\
\hline \multicolumn{9}{|l|}{ (B) } \\
\hline & & & & & \multicolumn{4}{|c|}{ Treatments } \\
\hline Set & Site & Species Planted & Planting Date & Ending Date & Planting Material $^{1}$ & Water Supplement $^{2}$ & Soil Preparation $^{3}$ & Soil Texture ${ }^{4}$ \\
\hline I & Kefraya & P. pinea & 15 April 2011 & 19 May 2013 & 10-mo, 12-mo bag seedlings & NIRR, IRR (10), RSW (5), NRSW (5) & MP & $\mathrm{Sd}$ \\
\hline I & Aitanit & P. pinea & 20 April 2011 & 19 May 2013 & 10-mo, 12-mo bag seedlings & NIRR, IRR (10), RSW (5), NRSW (5) & $\mathrm{HP}$ & SC \\
\hline I & Lala & P. pinea & 18 April 2011 & 19 May 2013 & 10-mo, 12-mo bag seedlings & NIRR, IRR (10), RSW (5), NRSW (5) & HP & SC \\
\hline II & Bkassin & P. pinea & 29 November 2011 & 28 November 2013 & $\begin{array}{l}\text { 8-mo contaniner, } 18 \text {-mo bag } \\
\text { seedlings; SP3 seeds; SS200 seed } \\
\text { sowing }\end{array}$ & NIRR, IRR (8) & $\mathrm{MP}, \mathrm{NP}$ & $\mathrm{Sd}$ \\
\hline II & Arz-Bcharre & C. libani & 13 November 2011 & 6 November 2013 & $\begin{array}{l}\text { 8-mo container, } 18 \text {-mo bag } \\
\text { seedlings; SP3 seeds; SS200 seed } \\
\text { sowing }\end{array}$ & NIRR, IRR (8) & $\mathrm{HP}, \mathrm{NP}$ & SC \\
\hline III & Bnabil & P. pinea & 7 January 2013 & \multirow{2}{*}{$\begin{array}{l}1 \text { July } 2014 \\
\begin{array}{l}\text { Destroyed by goats June 2013; } \\
\text { dropped }\end{array}\end{array}$} & SP3 seeds & NIRR & $\mathrm{MP}, \mathrm{HP}$ & $\mathrm{Sd}$ \\
\hline III & Kfarzebian & C. libani & 30 November 2012 & & $\mathrm{SP} 3$ seeds & NIRR & MP, HP & SC \\
\hline
\end{tabular}

${ }^{1}$ Seedlings were 8-, 10-, 12- or 18-month-old nursery stock grown in plastic bags (10-cm diameter, 20-cm length) or containers; 8- and 18-mo stock was higher quality because of nursery improvements. SP3 $=3$ seeds planted per basin (Set II), or 3 seeds per spot (Set III); SS200 $=200$ seeds sown in a patch. ${ }^{2}$ NRSW $=$ non-rechargeable solid water, RSW $=$ rechargeable solid water, IRR = conventional hose irrigation, NIRR = no irrigation; number of water additions or replacements over 2 years in parentheses. ${ }^{3} \mathrm{NP}=$ no preparation, $\mathrm{MP}=$ mechanical preparation (backhoe for Sets I and II and plowed for Set III), HP = hand tool preparation. ${ }^{4} \mathrm{Sd}=$ sandy soil with $38 \%$ or more sand particles, $\mathrm{SC}=$ silt and clay soil with $62 \%$ or more silt and clay particles where either can predominate; where sand $>0.05 \mathrm{~mm}$, silt $=0.002$ to $0.05 \mathrm{~mm}$, clay $<0.002 \mathrm{~mm}$. 
Soil was prepared in the least costly manner. On Kefraya, a Poclain or backhoe excavator dug planting holes (mechanical preparation, MP); workers with hand tools dug planting holes on Aitanit and Lala sites (hand preparation, HP) (Figure 3).

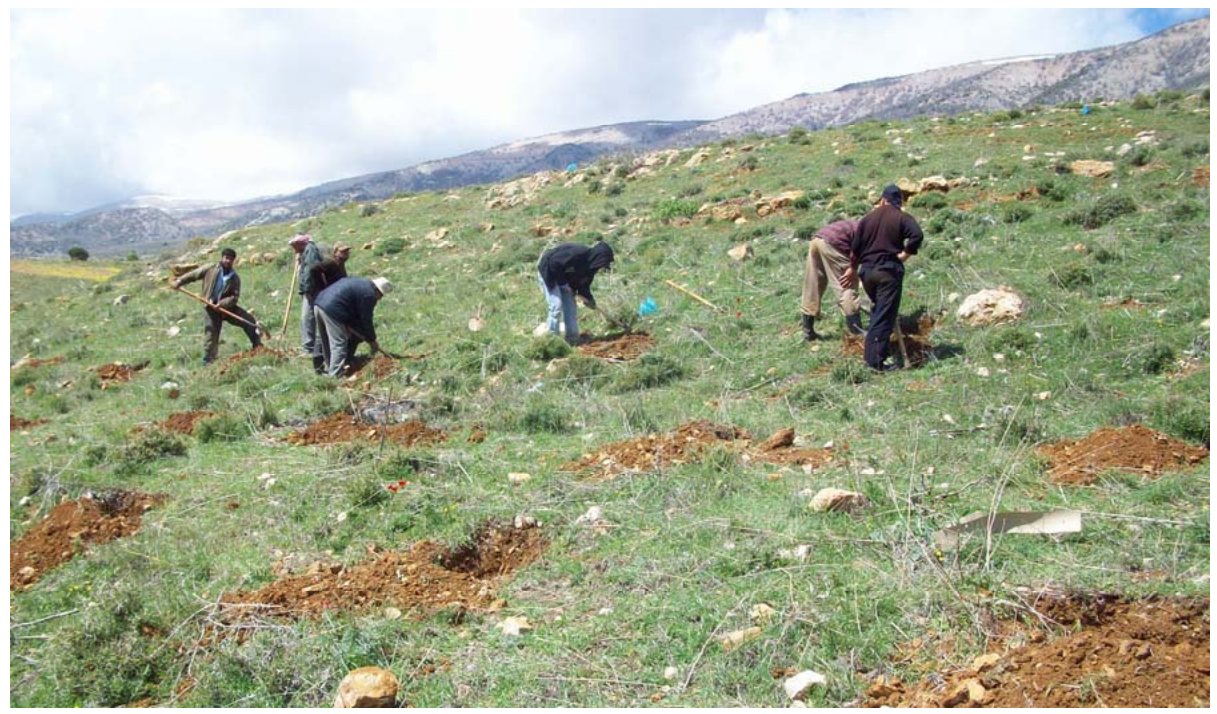

Figure 3. Hand preparation of Lala site.

Two novel irrigation methods-Rechargeable Solid Water (RSW) and Non-Rechargeable Solid Water (NRSW) - were used to test the effect of slow release of water on seedling survival compared to conventional hose irrigation and no irrigation; RSW and NRSW were obtained commercially and were without scientific documentation at time of study. RSW is a cross-linked polymer in a woven bag with a small amount of clay as an activator. RSW bags were charged, buried along the root zone of the seedlings (Figure 4), and recharged with a hose. NRSW is a $97 \%$ purified water and 3\% cellulose fiber compound that reduces water molecule vaporization. When it contacts soil, microbial action breaks down the cellulose fiber, gradually releasing water directly to the plant root zone (Figure 5). NRSW bags were replaced when dry.

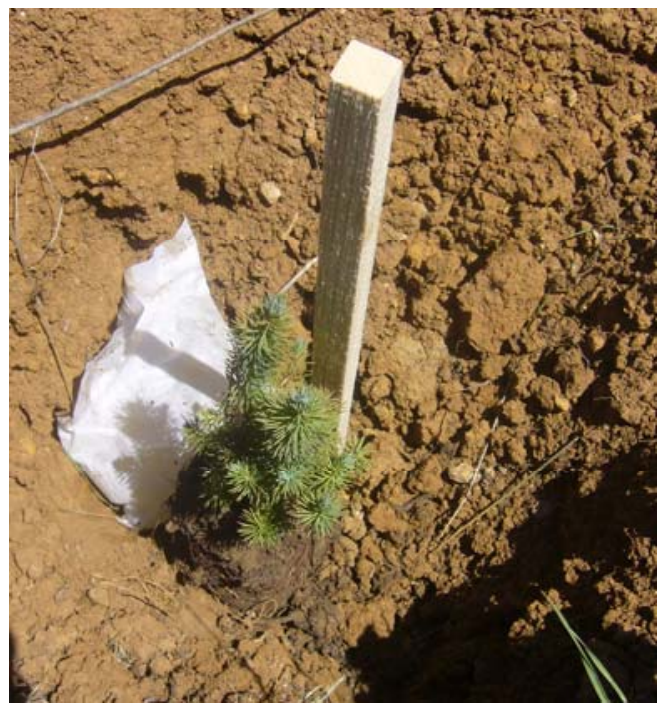

Figure 4. Rechargeable Solid Water (RSW) bag placed near stone pine root zone. Irrigation or rain can recharge bag for slow release. 


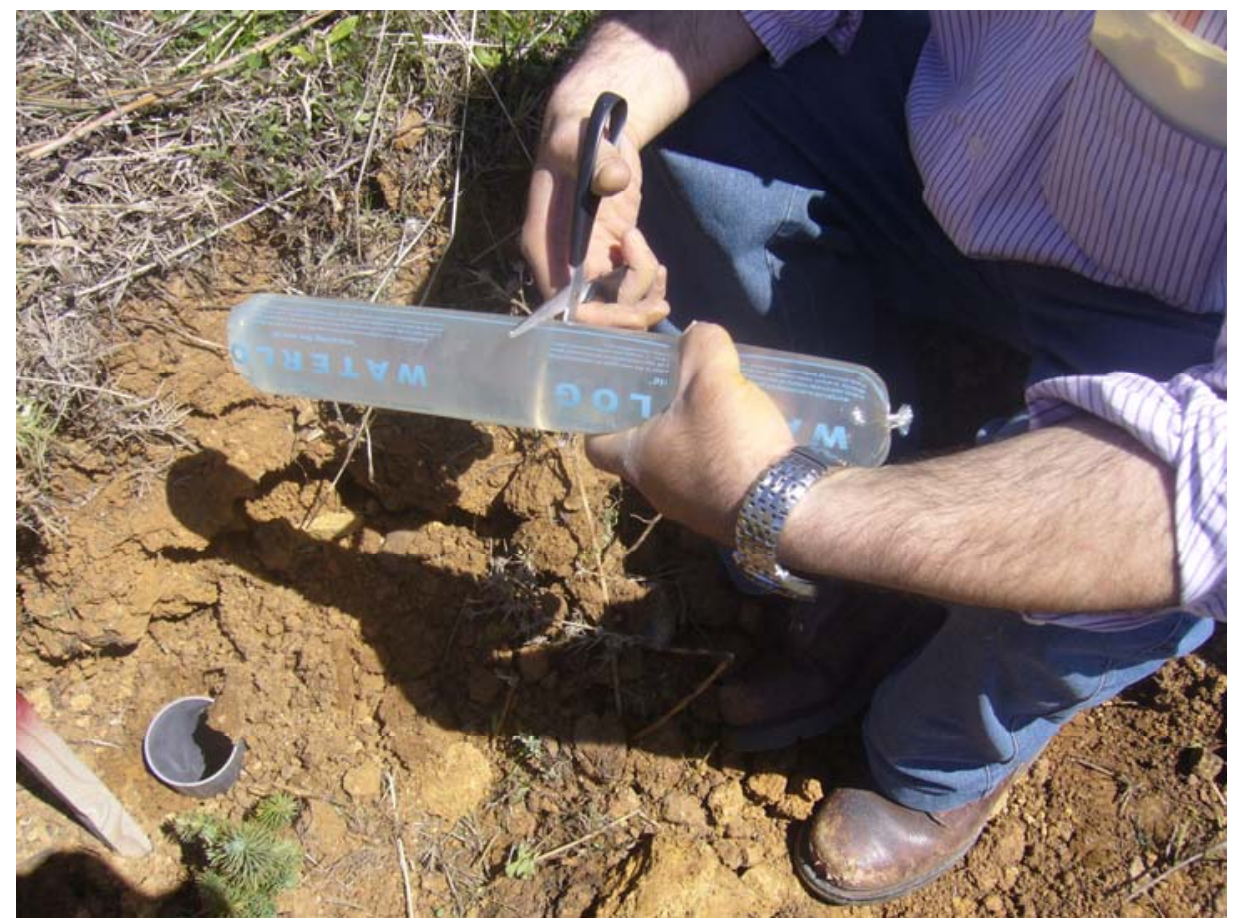

Figure 5. Each Non-Rechargeable Solid Water (NRSW) bag was cut in half; contents from one half bag were emptied into each of two PVC pipes buried on each side of each seedling so gel contacted wet soil. Pipes were capped to keep out soil and mulch.

\subsubsection{Set II Trials}

Fall planting at two sites for Set II trials examined (a) seedling survivability by age (8-mo and 18-mo) with irrigation (IRR) and no irrigation (NIRR); (b) seed planting with IRR and NIRR; and (c) seed sowing without irrigation comparing hand (HP) or mechanical (MP) soil preparation with no preparation (NP) (Table 1). Because Set I trials showed little difference between conventional irrigation and use of RSW and NRSW, only hose irrigation (IRR) was used for Set II-an example of the adaptive nature of this study.

Lebanon cedar seedlings and seeds were planted in Arz-Bcharre using HP; stone pine seedlings and seeds were planted in Bkassin using MP (Figure 1b). Each site covered about 0.4 ha. Seedling design was similar to Set I with 50 seedlings for each age and water treatment attribute, resulting in 200 per site. Seeds were (a) planted in rows of 3 seeds per small water-retention basin (SP3), similar to seedlings; or (b) sown and slightly covered with soil (1-2 cm), with 200 seeds in an area roughly $75 \mathrm{~m}^{2}$ (SS200), equivalent to about 25,000 seeds per ha. Design for SP3 seed planting was 50 basins for each water treatment attribute (100 per site). On each site, two seed sowings (SS200) were done-one for prepared soil (MP or HP) and one for unprepared soil (NP). Planting layout was adjusted for irregular site shape and to include seed sowing areas, which required flat terrain so seeds sown without soil preparation would not be washed away. Seedlings and seed basins were spaced at a density of about 800 per ha as for Set I. Although seed sowing was done more intensely, thinning would have been done to achieve a rate of 800 seedlings per ha had more seeds germinated.

Lebanon cedar seeds were collected just prior to use from mother trees in the same region as Arz-Bcharre; stone pine seeds were similarly collected from the forest of Bkassin. The 18-mo seedlings were produced through older nursery methods in use prior to introduction of improved nursery practices and grown in plastic bags as in Set I, while the 8-mo seedlings benefited from better planting containers (lightweight, 444-mL, slightly tapered, $6.4 \mathrm{~cm}$ in diameter and $17.8 \mathrm{~cm}$ long), hardening, and other new techniques. 


\subsubsection{Set III Trials}

Potential further cost reduction was sought in Set III by eliminating seedlings and irrigation, and effects of soil preparation methods were then tested with planted non-irrigated seeds (Table 1). These trials mimicked natural tree regeneration by using seed from trees in the region and timing planting so deep root systems could grow in time to help plants survive hot seasons without irrigation. Fall planting of stone pine seeds at Bnabil and Lebanon cedar at Kfarzebian was done on approximately 0.4-hectare sites. Stone pine seeds were collected from the Bnabil forest, and Lebanon cedar seeds from the same source areas as for Set II trials.

Plowing with a tractor (MP) was compared to lighter hand-tool preparation (HP). For each treatment, 150 spots (planting points without soil disturbance, in contrast to basin planting points designed for irrigation) were planted per site with 3 seeds per spot (SP3), not necessarily laid out in rows, and seeds covered with 1-2 cm of soil. Spots were spaced to achieve roughly 800 seedlings per hectare.

Although 150 spots were planted for each Bnabil treatment, only spots where at least one seedling germinated were tallied for the database (e.g., Bnabil data included 79 and 13 observations for respective HP and MP treatment attributes but we still assumed a sample size of 150 for each of these treatments for later calculations). On Kfarzebian, early germination was observed in May 2013, but there was still too much snow for an accurate seedling count and the site was subsequently devastated by goats, so neither initial germination nor survival could be assessed and the site was deleted from analysis.

\subsection{Data Compilation}

Raw data from the adaptive field trials were compiled, summarized, and visually examined prior to statistical analysis and subsequent comparison of survival to cost. Statistical analysis was conducted as a guide for data interpretation with the goal of looking for trends, not determining absolute survival rates or strictly significant/nonsignificant findings. Inconsistency and low replication (insufficient sample size) among sets required some preliminary assumptions, groupings, and calculations before statistical analysis tools could be used to tease out treatment effects.

\subsubsection{Survival and Germination}

A database of 1896 file observations was constructed for survival and germination data (1200 for Set I, 604 for Set II, and 92 for Set III). The database was organized by sets, sites, treatment variables, and tree number; with germination (from seed planting and sowing) and survival data arrayed by month or period of data collection. Measurement period ranged from date 0 (initial planting month) through 22 (22 consecutive dates) with four additional quarterly periods needed for Sets II and III. This placed data from all three sets into a uniform database for analysis.

Several assumptions were made to harmonize data and to maximize replication by grouping prior to statistical analysis: seed planting (SP3) techniques in Sets II and III were assumed to be similar even though differed slightly; soil preparation methods—mechanical (MP) and hand tool (HP)—were generally grouped to be compared to no soil preparation (NP); and seedling ages were grouped as 8-10 mo, $12 \mathrm{mo}$, and $18 \mathrm{mo}$. Soil data collected at each site was used to identify soils as sandy (at least $38 \%$ sand; Sd) or silt-clay (greater than $38 \%$ silt or clay; SC).

Seedling survival was calculated as the percentage of seedlings surviving at a given measurement period, but to allow comparison of seedlings with seed planting and sowing, germination had to be considered. Outplanted seedlings automatically comprise $100 \%$ germination success (because ungerminated seeds are culled in the nursery) but seeding treatments could yield poor germination from factors unrelated to treatment and yet, because of treatment, have good survival of the seeds that germinated. Study of germination was not an objective of the original field trials and limited data unfortunately resulted in too little replication to independently statistically analyze it. Because 
we wanted to minimize confounding germination effects in our analysis, a weighted survival metric (devised from simulation graphs of all possible outcomes) was used to compensate for potentially misleading results of low germination with high survival and allow comparison of seedling and seed performance on a common basis.

Germination for seed-planting treatments (SP3) was calculated as the sum of points where one or more seeds germinated; then this number was divided by the total number of points planted for a given treatment (expressed as a percentage). Germination for seed sowing (SS200) was determined by dividing total seeds that germinated by total seeds sown (also expressed as a percentage).

Next, for planting points (SP3) where at least one seed germinated, survival was similarly tallied after two growing seasons and divided by germination tally (with the result expressed as a percentage). For the seeds sown (SS200), seedling survival from those initially germinated was also expressed as a percentage of germination tally.

If the survival percentage (for either SP3 or SS200) was less than or equal to the germination percentage, it was used in subsequent analyses. If survival percentage was larger than germination percentage, it was reduced by averaging with germination percentage to calculate a weighted survival value. As an example, the weighted survival when all seedlings survive from a germination of $5 \%$ would be $(100+5) / 2=53 \%$. In the analyses and discussion below, survival refers to survival as determined by this weighted process.

\subsubsection{Costs}

Expense data were summarized from itemized costs, including those for planting material, outplanting labor, irrigation, soil preparation, and maintenance (for more detail see [24]). Total costs were expressed on a per-hectare basis by assuming 800 seedlings per ha.

\subsection{Statistical Analysis}

Each of the six sites where data were collected was considered an "experimental unit" for statistical analysis of site and treatment effects on survival. This allowed experimental treatments to be replicated among sites. Treatment variables included (a) planting material (seedling age or seeding method); (b) water (irrigation method or none); (c) soil texture; and (d) soil preparation (Table 1). The trials were not designed to consider soil texture as a treatment variable, and soil preparation was only considered a treatment in Set III and for a small portion of Set II (SS200). However, sufficient replication of these two factors when all sites were combined allowed their evaluation as "treatments" for statistical analysis.

Tree survival at the last measurement period (after two growing seasons) was selected for analysis for each unique treatment attribute combination, resulting in 42 treatment combinations to analyze for all sites combined. To better harmonize data among all sets and increase replications (increase sample size) to test treatment effects, planting material and site preparation variable values were further grouped. Because younger and older seedlings were compared in Set I (8-to-10-mo vs. 12-mo) and Set II (8-mo vs. 18-mo), seedlings were grouped into 8-10 months and 12-18 months, corresponding to younger and older groups. Soil preparation had not been designed as a treatment variable for Set I and most of Set II, so there was insufficient replication (too small sample size) to test between all types; mechanical (MP) and hand (HP) preparation were grouped together as soil preparation (sp) and compared to no preparation (NP or $\mathrm{np}$ ). For Set III data, heavy mechanical preparation (plowing) was considered soil preparation (sp) and the minimal hand preparation for planting seeds in spots (no soil disturbance) considered no preparation (np).

These additional groupings reduced 42 treatment combinations to $25,1-3$ replications each, with 4 variables:

- $\quad$ Planting material: 8-to-10-mo and 12-to-18-mo seedlings, 3 seeds per planting point (SP3), and sown (SS200)

- Water: no irrigation (NIRR), conventional irrigation (IRR), rechargeable solid water (RSW), and non-rechargeable solid water (NSRW) 
- Soil preparation: mechanical or hand tool (sp) and none (np)

- Soil texture: sandy (Sd) and silt-clay (SC)

Generalized linear mixed models (hereafter called mixed models) were used to test for significance of treatment effects among the 6 sites. Mixed models is a generalization of the standard linear model used in regression; the generalization allows more flexibility for modeling variance structures [25]. This allowed for significance testing among sites for the field trials data.

The analysis considered the treatments as fixed effects for testing but accounted for site effects as random effects so treatments across all sites could be reasonably assessed. A convenient artifact of this analysis was that because only a single species was used on each site, it also adjusted for species differences as part of random effects. Hence, Arz-Bcharre-the only Lebanon cedar site remaining after the loss of Set III trials on Kfarzebian from grazing-could be included with the stone pine sites for treatment assessments. Individual treatment attributes were also examined with pairwise $t$-tests (using Tukey-adjusted $p$-values for testing treatments with more than 2 attributes) to evaluate which attributes significantly affected survival.

Mixed-models analysis uses a mathematical equation best expressed in matrix algebra and not listed here. Of the two ways to account for sites in mixed-models analysis using SAS/STAT ${ }^{\circledR}$ software, "Repeated" with compound symmetry (CS) covariance structures [26] was selected, not "Random" model formulation. SAS consultants [27] helped with this choice to give the most flexibility for convergence when estimating covariance structure. The exact model set up in SAS/STAT ${ }^{\circledR}$ software was

Proc Mixed Data = datafile;

Class Site Planting_method Water_supplement Soil_texture Soil_preparation;

Model Survival = Planting_method Water_supplement Soil_texture Soil_preparation;

Repeated $/$ Type $=$ CS Subject $=$ Site;

Lsmeans Planting_method Water_supplement Soil_texture Soil_preparation/Pdiff

Adjust = Tukey;

Run;

Mixed-models analysis model fit was reasonable for most treatment combinations, as evidenced by examining statistical graphics of model fit (figure not shown). This added confidence for interpreting statistical results, even though replication was low (i.e., small sample size).

\section{Results}

\subsection{Survival and Cost Overview of All Treatments}

Survival in the original 42 treatment combinations (Figure 6, statistical graph) ranged from zero (for 4 treatments at Lala and Arz-Bcharre) to about 85\% (Kefraya 12-mo NRSW Sd MP). Generally, treatment combinations on sandy soils or irrigated silt-clay soils had the highest survival, as did some sites (e.g., Kefraya). However, there was no clear pattern of survival with planting material, particularly seedling age.

Cost details are provided in the full UNDP report [24] but summarized here in a statistical graph (Figure 7). The most expensive site treatments included NRSW and cost more than 10,000 USD/ha. Treatments with conventional irrigation (IRR) ranged in cost from about 2000 USD/ha (for seeds) to 6000 USD/ha (seedlings); RSW treatments cost about 4500 USD/ha. Non-irrigated treatment (NIRR) costs were about 2000-4000 USD/ha with seedlings, and only about 10-1000 USD/ha with seeds.

While the visual examination of this complex dataset through statistical graphs revealed useful information helpful in directing further analyses, it was difficult to use the graphs to draw conclusions. For example, although irrigation (particularly NRSW) is clearly shown to be a major cost factor (in Figure 7), secondary cost drivers are obscured. Overall there were too many variables to assess these data without help from statistical analysis. Consequently, we reduced the treatment combinations to 
25 by grouping as described above and utilized the flexible mixed-models analysis to assess significant treatment effects.

\subsection{Statistical Significance of Treatment Effects}

The mixed-models analysis of treatment effects on survival showed two significant treatment effects for water supplement and soil texture ( $p$-values 0.0038 and $<0.0001$ respectively, where $p<0.05$ is significant; Table 2), indicating some water treatments and soil textures affected plant survival. No significant difference was detected among planting materials (seeds or seedling age; $p$-value $=0.2055$ ) or among soil preparation methods $(p$-value $=0.4409)$.

For treatments with more than two attributes (Numerator DF $>1$ in Table 2), finer scale pairwise comparisons were examined to see which attributes were statistically different (table not shown). Tests were done with Tukey adjustment to allow for multiple comparisons. For example, no irrigation significantly affected planting material survival when compared to novel water supplements (Tukey adjusted $p$-values 0.0036 and 0.0379 for comparison of NIRR with NRSW and RSW).

Interestingly, conventional irrigation (IRR) was not significantly different from either NRSW or RSW novel irrigation treatments, nor was NRSW significantly different from RSW (Tukey adjusted $p$-values $0.0846,0.7674$ and 0.4755 , respectively). This indicates that a water supplement can be selected for cost or availability without concern for which method is better.

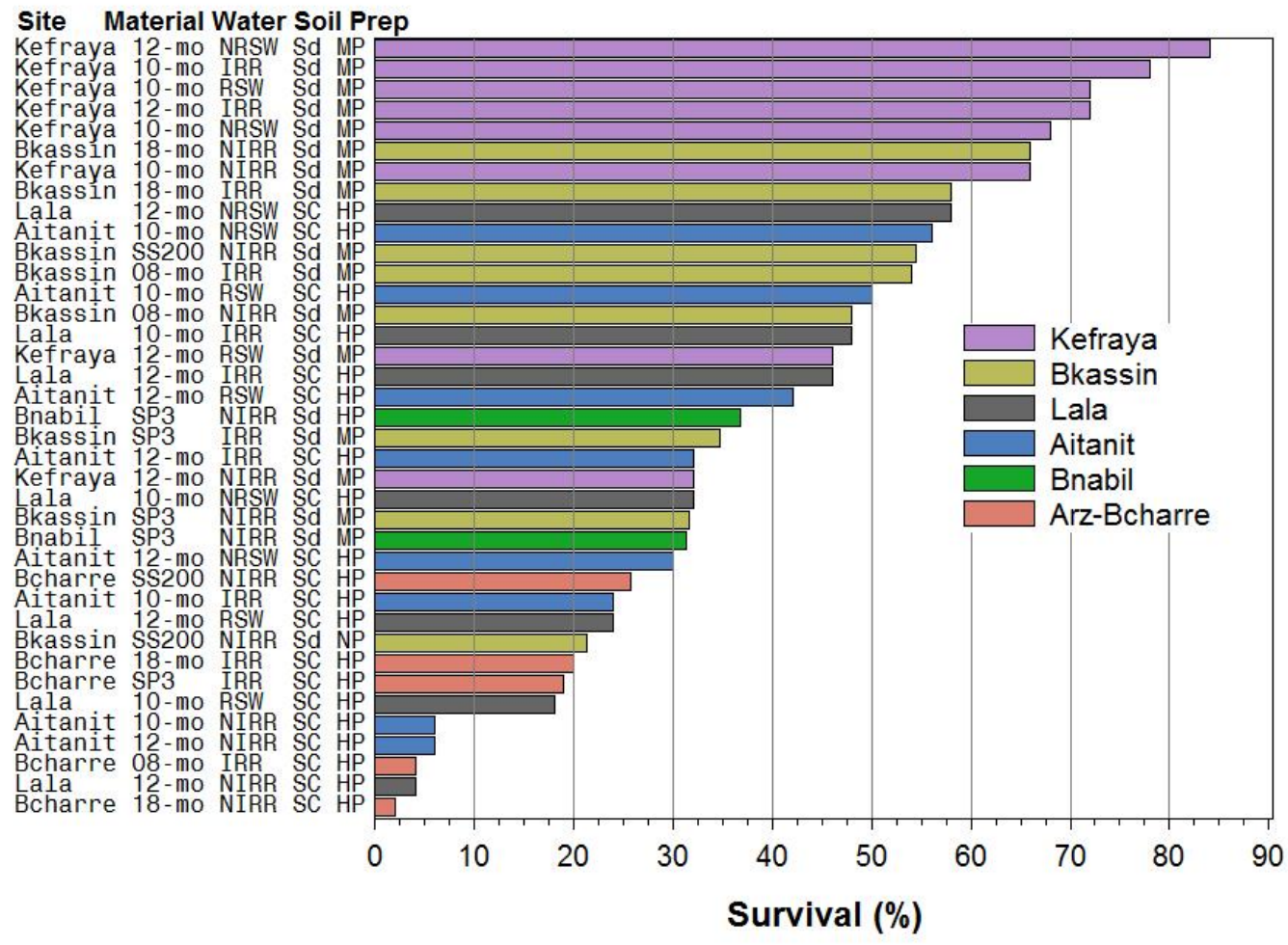

Figure 6. Survival in 42 planting treatment combinations. Not shown are four with zero survival: Lala 10-mo NIRR SC HP, Bcharre 08-mo NIRR SC HP, Bcharre SP3 NIRR SC HP, and Bcharre SS200 NIRR SC NP. Plantings at Arz-Bcharre (Bcharre in figure) were Lebanon cedar; all others were stone pine. Treatment attributes (on $y$-axis) included those for planting material (8-, 10-, 12-, and 18-month-old seedlings; SS200 = 200 seeds sown in patch; SP3 = 3 seeds planted at points), water supplement (NRSW = non-rechargeable solid water, RSW = rechargeable solid water, IRR = conventional hose irrigation, $\mathrm{NIRR}=$ no irrigation), soil texture ( $\mathrm{Sd}=$ sandy, $\mathrm{SC}=$ silt-clay), and soil preparation $(\mathrm{MP}=$ mechanical preparation, $\mathrm{HP}=$ hand tool preparation, $\mathrm{NP}=$ no preparation). 


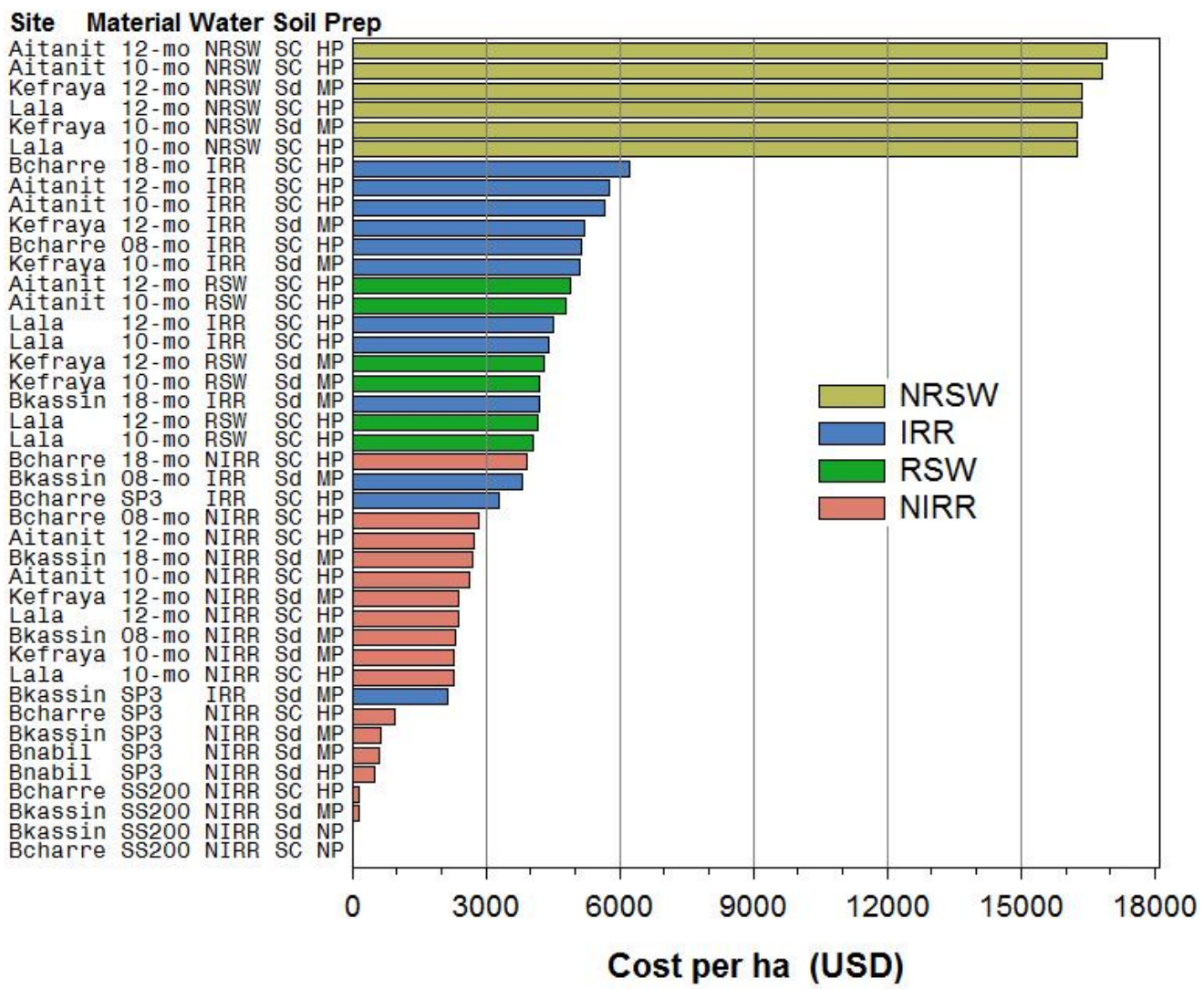

Figure 7. Cost of each of 42 planting treatment combinations. Plantings at Arz-Bcharre (Bcharre in figure) were Lebanon cedar; all others were stone pine. Treatment attributes (on $y$-axis) included those for planting material (8-, 10-, 12-, and 18-month-old seedlings; SS200 = 200 seeds sown in patch; SP3 $=3$ seeds planted at points), water supplement (NRSW $=$ non-rechargeable solid water, RSW = rechargeable solid water, $\mathrm{IRR}=$ conventional hose irrigation, $\mathrm{NIRR}=$ no irrigation), soil texture $(\mathrm{Sd}=$ sandy, $\mathrm{SC}=$ silt-clay), and soil preparation $(\mathrm{MP}=$ mechanical preparation, $\mathrm{HP}=$ hand tool preparation, $\mathrm{NP}=$ no preparation).

Table 2. Linear mixed-models statistical tests for 4 fixed-treatment effects (while adjusting for 6 "repeated" or random-like site effects) showing significance or nonsignificance.

\begin{tabular}{|c|c|c|c|c|c|}
\hline Fixed-Treatment Effect & $\begin{array}{c}\text { Numerator } \\
\text { DF }\end{array}$ & $\begin{array}{c}\text { Denominator } \\
\text { DF }\end{array}$ & F-Value & Prob $>F$ & \\
\hline Planting method (seedling age or seeding method) & 3 & 6 & 2.07 & 0.2055 & ns \\
\hline Water supplement & 3 & 8 & 10.46 & 0.0038 & * \\
\hline Soil texture & 1 & 4 & 738.11 & $<0.0001$ & * \\
\hline Soil preparation & 1 & 2 & 0.91 & 0.4409 & ns \\
\hline
\end{tabular}

* significant at 0.05 probability level, ns: nonsignificant.

Planting material—seedlings of different ages or seeds—did not affect survival overall (Tukey adjusted $p$-values 0.2 and larger). Therefore, planting materials can be chosen based on cost without too much concern about seeds vs. seedlings. However, this result only applied to survival of seeds planted and sown that germinated, and ignored poor germination rate (an important consideration further discussed below). It was somewhat surprising that survival from the younger seedling age class (8-10 mo) did not differ significantly from the older age class (12-18 mo) because more costly older seedlings generally are assumed to survive better-although our statistical graph (Figure 6) also showed little relationship of survival to seedling age. 


\subsection{Interpretation of Statistical Results in Relation to Cost}

The statistical findings-though useful for narrowing treatment effects into a manageable subset from the 42 treatment combinations across 6 sites-were inadequate to produce the practical recommendations needed by the project for treatments that resulted in both acceptable survival and costs. These came from comparing statistical results with planting trial costs, further grouping the treatments, and reexamining survival with respect to cost.

Nonsignificant treatment attributes were combined when costs were similar. For planting materials, there were no significant differences (Table 2) among seedling ages (8-10 mo, 12 mo, $18 \mathrm{mo}$ ); however, 18-mo seedlings were generally more costly than younger seedlings so they were separately compared to all younger seedlings (8-12 mo). Seed treatments (SP3 and SS200) were kept separate because of planting cost differences.

NRSW treatment combinations were so costly (Figure 7) they were excluded from the above analysis and considered separately. Likewise, the Arz-Bcharre data were kept separate because they came from the only Lebanon cedar site. This left 13 treatment combinations that could be considered for stone pine establishment. Some of these combinations were replicated more than once on different sites for a total of 28 observations to compare with cost.

Cost per ha for stone pine establishment and maintenance for two years was averaged for the 13 treatment combinations for comparison to survival (Figure 8). Replication was small (1 to 4) in many cases but strategic selection of the 28 attribute combinations resulted in low variance when averaging costs. (For example, standard error divided by mean ranged from 1\% to 10\% for combinations with 2 or more replications.) Overall, Figure 8 shows that seeding treatments (SP3 and SS200) can achieve survival results similar to seedlings in some cases and that irrigation greatly increases establishment costs. For seeding treatments, germination was also included in the graphical comparison (brown bar; on top of green survival bar if less than survival, underneath if greater than survival), because even though survival was weighted to account for poor germination, poor germination is still a problem to be overcome before a treatment can be recommended.
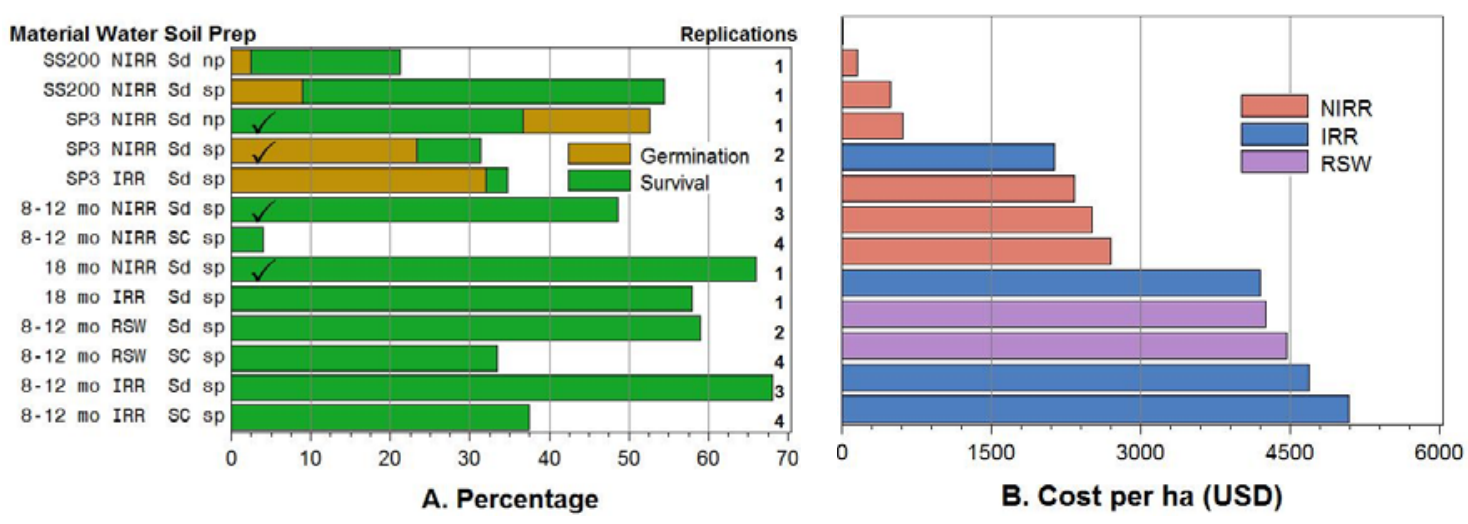

Figure 8. (A) Stone pine (Pinus pinea) percent survival (and germination for seed treatment combinations) compared to (B) cost in U.S. dollars for establishment and 2 years' maintenance. For treatments with seeds, germination or survival is overlaid (bars not stacked) depending upon which is larger. Survival generally exceeded germination because it was adjusted for germination (see text) to put seeds and seedlings on a more comparable basis. Treatment attributes (on $y$-axis) include those for planting material (8-to-12- and 18-month-old seedlings, SS200 $=200$ seeds sown in patch, SP3 = 3 seeds planted at points), water supplement (RSW = rechargeable solid water, IRR = conventional hose irrigation, NIRR = no irrigation), soil texture ( $\mathrm{Sd}=$ sandy, $\mathrm{SC}=$ silt-clay), and soil preparation variables $(\mathrm{np}=$ no preparation, $\mathrm{sp}=$ mechanical or hand-tool preparation). Replications $>1$ indicate survival and germination and cost estimate values were averaged. Cost for SS200 NIRR Sd np is 14 USD (barely visible). Treatment attribute combinations with checkmark cost less than 3000 USD and are recommended. 


\section{Discussion}

Based on the above analysis of survival and costs (e.g., Figure 8), we discuss planting trial results in terms of cost-effective survival. We start by eliminating treatments that performed poorly or were costly without appreciably improving survival, and progress to those that were most cost-effective.

\subsection{Stone Pine Treatments Not Recommended}

Although seed sowing (SS200) with no irrigation was inexpensive, seeds germinated too poorly (or were too highly predated) to recommend this method (SS200 NIRR Sd np, SS200 NIRR Sd sp). However, more research into seed sowing might be worthwhile, because when site soil was prepared (SS200 NIRR Sd sp), seedlings survived well from the small number of seeds that germinated. This observation is also consistent with other literature [13]. Mechanical soil preparation may aid rapid root development or water retention, as was found in planting work in Spain [28].

The 8-12-mo seedlings planted on silt-clay soils survived too poorly without irrigation (8-12 mo NIRR SC sp) to recommend that combination. Although water supplementation improved seedling survival (8-12 mo RSW SC sp, 8-12 mo IRR SC sp), plants still survived only half as well as in similar treatments on sandy soil, corroborating observations that pines prefer sandy soil [22]. Even with irrigation, planting stone pine on silt-clay soils should be avoided until more is known.

Interestingly, seeds planted with irrigation (SP3 IRR Sd sp) survived little better than seeds planted without irrigation (SP3 NIRR Sd sp, SP3 NIRR Sd np) (Figure 8). Although it did not fit the overall statistical testing results (which found NIRR significantly different from IRR on average for all planting materials), this observation suggests costly irrigation might not be needed for seed plantings on sandy soils. Further study could resolve the question of whether irrigation is useful in these cases.

No treatments costing more than $3000 \mathrm{USD} /$ ha were recommended for establishing stone pine seedlings because the added irrigation cost did not correspond to a survival rate appreciably greater than that of non-irrigated seedling treatments (18 mo IRR Sd sp, 8-12 mo RSW Sd sp, and 8-12 mo IRR Sd sp compared to NIRR treatments).

As discussed above, NRSW treatment combinations were eliminated prior to survival-cost analysis because they were prohibitively expensive. Although they produced the best survival for $8-12$-mo seedlings (76\% for sandy soil and $44 \%$ for silt-clay), this was not appreciably better than survival with much cheaper water supplements (IRR and RSW), at about $60-70 \%$ and $30-40 \%$ survival in sandy and silt-clay soils, respectively.

\subsection{Inconclusive Lebanon Cedar Treatments}

A cost analysis separate from that in Figure 8 was done for Lebanon cedar. Although limited data (only 1 silt-clay site) and poor survival (0-25\%) precluded planting recommendations for this species, anecdotal evidence indicates promising results that should be tested further.

Non-irrigated seed plantings and sowing cost less than 1500 USD/ ha, but only one seed sowing treatment combination (SS200 NIRR SC sp) yielded survival greater than zero, at about $25 \%$. Using seedlings and/or irrigation increased costs to $3000 \mathrm{USD} /$ ha or more for only $0-20 \%$ survival. Treatment combinations with $20 \%$ survival included irrigated seed and 18-mo seedling plantings (SP3 IRR SC sp and 18 mo IRR SC sp) at costs of about 3000 and 6000 USD/ha, respectively.

Germination of seed plantings (SP3) was about $50-75 \%$. Although they survived poorly even with irrigation, this offers anecdotal evidence that Lebanon cedar germinates reasonably well on silt-clay. If survival from germinated seed could be improved, Lebanon cedar might be established for less than 1500 USD/ha without irrigation and about twice that cost with irrigation.

\subsection{Stone Pine Treatments Recommended}

After stone pine and Lebanon cedar treatments were eliminated as above, four treatment combinations remained for serious consideration for stone pine planting practices. All were for 
sandy soils and omitted irrigation (i.e., checked treatments in Figure 8). The study did not offer well-substantiated recommendations for successfully planting stone pine on silt-clay soils or for Lebanon cedar.

Among seed planting treatment combinations, the most cost-effective recommendations ( $<600$ USD/ha) were non-irrigated seed plantings with or without soil preparation (SP3 NIRR Sd $\mathrm{sp}$ and SP3 NIRR Sd np), which had survival rates near $35 \%$ but widely differing germination rates (Figure 8). The poor germination could be due to soil preparation, but we were unable to test this because germination data included too few replications (see companion report [24]). Anecdotal observations of the two SP3 treatment combinations suggested that seeds planted on prepared sites (sp), once germinated, survived better than those germinated on sites with less soil preparation.

The next most cost-effective recommendations (about $2500 \mathrm{USD} / \mathrm{ha}$ ) include seedlings planted on sandy soils without irrigation (8-12 mo NIRR Sd sp, 18 mo NIRR Sd sp), with approximately 50-70\% survival. Use of 18 -mo seedlings gave $20 \%$ greater survival than $8-12$-mo seedlings (although not statistically different), but cost about $500 \mathrm{USD} /$ ha more (Figure 8). The non-irrigated seedlings showed $15 \%$ to $30 \%$ greater survival than seed planting but cost about 4 times as much.

\subsection{Larger Scale Applications}

Some of the techniques from these field trials have been applied on a larger scale on 8 areas throughout Lebanon comprising 25 ha. They were planted with 8-mo seedlings or seed spots (SP3), in autumn or winter 2013-2014 after the first rain. Four sites received no supplemental irrigation. Depending on the site, stone pine, cedar, and/or other species were planted. One non-irrigated site, Wadi Al-Karm, was reforested with stone pine seed planting (SP3) and 8-mo seedlings, working with the monastery landowner after a fire on more than 10 ha of pine forest in 2013. Initial monitoring in August 2014, after the dry summer season, showed 72\% average survival from seeds (seedlings generated from seeds planted) and 100\% survival of the 8-mo seedlings (Figure 9). This anecdotal evidence indicates at least initial success with low-cost, no-irrigation planting methods. Monitoring of other large-scale reforestation efforts in Lebanon that are using these methods could help identify the best conditions for their success.

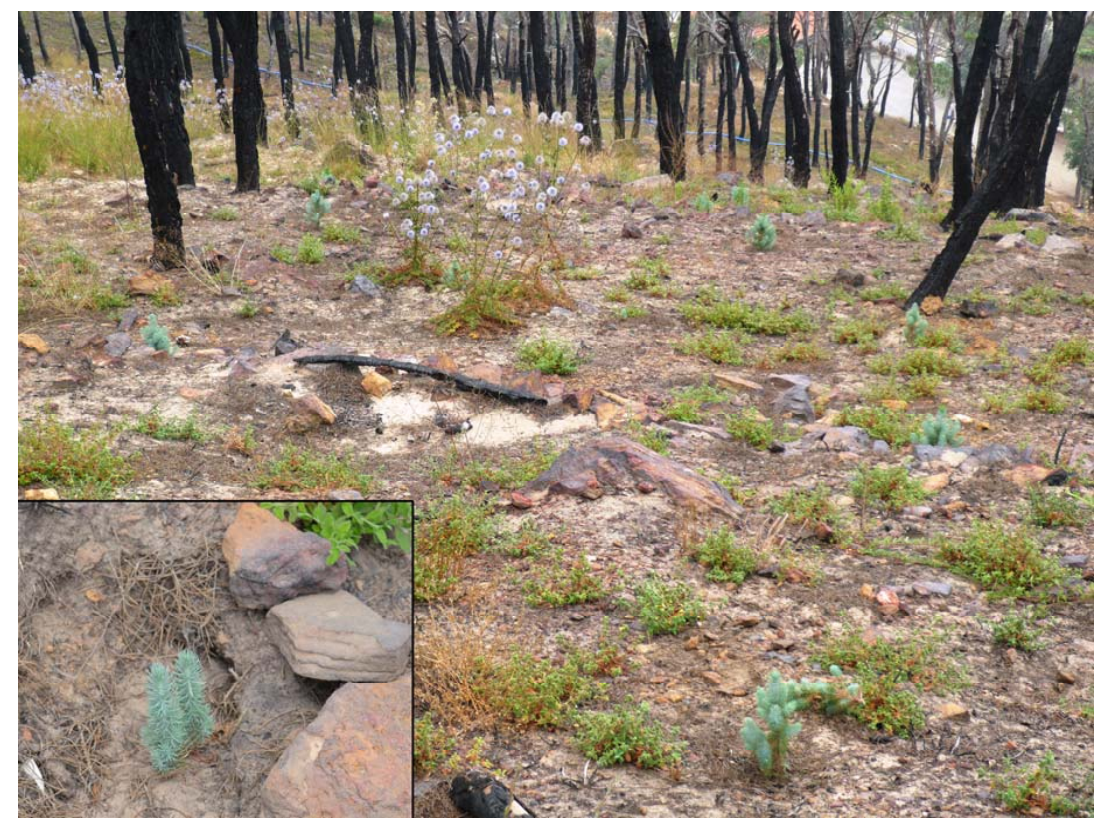

Figure 9. Stone pine planted at Wadi Al-Karm, Lebanon. 100\% of 8-month seedlings survived after 1 year; survival from seeds was $72 \%$. Inset shows 2 of 3 seeds planted in a spot that have germinated and survived. 


\section{Conclusions}

- Planting seeds on arid lands using an appropriate seed source under correct conditions shows great promise.

- Based on our survival analysis and cost comparison of treatments from field trials conducted in Lebanon, recommendations are given for planting stone pine; these apply only to planting on sandy soil:

- Seeds collected from nearby mother trees and planted in spots or basins, three to a basin, without irrigation, were the most promising low-cost technique.

Using seedlings (8- to 18-mo nursery stock) without irrigation can increase survival by 15 to 30 percentage points—-but can approximately quadruple establishment costs over 2 years.

- Water supplementation increased costs but did not appreciably increase survival.

- Conventional (hose) irrigation and novel water supplements (Non-rechargeable Solid Water [NRSW] and Rechargeable Solid Water [RSW]) all had similar effects on survival. NRSW was too expensive ( $>16,000$ USD per ha) for serious consideration. RSW cost about the same as conventional irrigation (4000 to $5000 \mathrm{USD} / \mathrm{ha}$ ), and was even a little cheaper in some cases. RSW also required fewer applications than conventional irrigation and might be useful in case of water shortages.

- Several topics merit further study:

Soil texture and soil preparation effects on survival for each species.

Germination in stone pine, particularly in fine-textured soils.

Improvement of Lebanon cedar survival after germination.

Acknowledgments: This study was funded as part of a larger project, “Safeguarding and Restoring Lebanon's Woodland Resources Project (SRLWRP) 2010-2014", which funded planting trials and other initiatives to improve Lebanon reforestation. SRLWRP was jointly funded by the Global Environmental Facility (GEF) and the Government of Lebanon and implemented by United Nations Development Programme (UNDP) in partnership with the Lebanon Ministry of Environment. Analysis of field trial data was done by the second author, DC Chojnacky, as part of a 2014 UNDP contract to write the final project report for SRLWRP. Open access publication cost was paid by University Libraries, Virginia Polytechnic Institute and State University through their Open Access Subvention Fund (OASF). MS Redmond of Scientific Notations LLC helped with literature review research and considerable editing and revising of the manuscript and SRLWRP report. Authors are grateful to two anonymous reviewers for their comments and observations. The data analysis for this paper was done using SAS/STAT ${ }^{\circledR}$ software, Version 9.4 of the SAS System for Windows 7. Copyright $@ 2012$ SAS Institute Inc. SAS and all other SAS Institute Inc. product or service names are registered trademarks or trademarks of SAS Institute Inc., Cary, NC, USA.

Author Contributions: G.H. provided overall project management and leadership for coordination of many entities, study design, site selection, and implementation decisions; and supported and reviewed D.C.C.'s writing of the manuscript. D.C.C. also designed and conducted statistical analysis which led to the findings, conclusions, and overall development of the manuscript. R.E.R. implemented all aspects of the field trials including treatment layout, measurements, monitoring, recording, and photography. C.C.C. coordinated communication, led research into background literature and context, and contributed to manuscript writing and editing.

Conflicts of Interest: The authors declare no conflict of interest; the manuscript was written by the second author after all funding had expired. The funding sponsors had no role in the design of the study; in the collection, analyses, or interpretation of data; in the writing of the manuscript; or in the decision to publish the results.

\section{References}

1. Talhouk, S.N.; Zurayk, R.; Khuri, S. Conservation of the coniferous forests of Lebanon: Past, present and future prospects. Oryx 2001, 35, 206-215. [CrossRef]

2. United Nations Development Programme (UNDP). Safeguarding and Restoring Lebanon's Woodland Resources Project Document, Funding Request from the Global Environmental Facility; United Nations Development Programme (UNDP): Beirut, Lebanon, 2008; unpublished. 
3. Dalsgaard, S. (Ed.) National Forest and Tree Assessment and Inventory: Final Report; Food and Agriculture Organization of the United Nations (FAO) Report No. TCP/LEB/2903; Republic of Lebanon, Ministry of Agriculture: Beirut, Lebanon, 2005.

4. Yasuda, Y.; Kitagawa, H.; Nakagawa, T. The earliest record of major anthropogenic deforestation in the Ghab Valley, northwest Syria: A palynological study. Quat. Int. 2000, 73-74, 127-136. [CrossRef]

5. Mikesell, M.W. The deforestation of Mount Lebanon. Geogr. Rev. 1969, 59, 1-28. [CrossRef]

6. Masri, R. The Cedars of Lebanon: Significance, Awareness and Management of the Cedrus Libani in Lebanon; Transcript of Talk Presented at Cedars Awareness and Salvation Effort Seminar; Massachusetts Institute of Technology: Cambridge, MA, USA, 1995. Available online: http://almashriq.hiof.no/lebanon/300/360/ 363/363.7/cedars2.html (accessed on 22 August 2014).

7. The International Union for Conservation of Nature and Natural Resources (IUCN) Red List of Threatened Species, Version 2014.2. Available online: www.iucnredlist.org (accessed on 22 August 2014).

8. Hitti, P. A Short History of Lebanon; Macmillan: London, UK, 1965.

9. Sfeir, P.R. Stone Pine and Pine Nuts Production in Lebanon. Presented at Agropine2011: International Meeting on Mediterranean Stone Pine for Agroforestry, PRAE, Valladolid, Spain, 17-19 November 2011. Available online: http:/ / networks.iamz.ciheam.org/agropine2011/PDFs_ponencias/RT-4.Production_in_ Lebanon_P.R.Sfeir.pdf (accessed on 9 May 2017).

10. Gülcü, S.; Gültekin, H.C.; Ölmez, Z. The effects of sowing time and depth on germination and seedling percentage of the Taurus Cedar (Cedrus libani A. Rich.). Afr. J. Biotechnol. 2010, 9, 2267-2275.

11. Boydak, M. Regeneration of Lebanon cedar (Cedrus libani A. Rich.) on karstic lands in Turkey. For. Ecol. Manag. 2003, 178, 231-243. [CrossRef]

12. Villar-Salvador, P.; Peñuelas, J.L.; Jacobs, D.F. Nitrogen nutrition and drought hardening exert opposite effects on the stress tolerance of Pinus pinea L. seedlings. Tree Physiol. 2013, 33, 221-232. [CrossRef] [PubMed]

13. Bainbridge, D.A. A Guide for Desert and Dryland Restoration: New Hope for Arid Lands. The Science and Practice of Ecological Restoration; Island Press: Washington, DC, USA, 2007.

14. Dominguez-Lerena, S.; Sierra, N.H.; Manzano, I.C.; Bueno, L.O.; Rubira, J.P.; Mexal, J.G. Container characteristics influence Pinus pinea seedling development in the nursery and field. For. Ecol. Manag. 2006, 221, 63-71. [CrossRef]

15. Chirino, E.; Vilagrosa, A.; Cortina, J.; Valdecantos, A.; Fuentes, D.; Trubat, R.; Luis, V.C.; Puértolas, J.; Bautista, S.; Baeza, J. Ecological restoration in degraded drylands: The need to improve the seedling quality and site conditions in the field. In Forest Management; Grossberg, S., Ed.; Nova Science Publishers, Inc.: New York, NY, USA, 2009; pp. 85-158.

16. Barnett, J.P. Direct Seeding Southern Pines: History and Status of a Technique Developed for Restoring Cutover Forests; General Technical Report SRS-187; USDA Forest Service, Southern Research Station: Asheville, NC, USA, 2014.

17. Boydak, M. Reforestation of Lebanon cedar (Cedrus libani A. Rich.) in bare karstic lands by broadcast seeding in Turkey. In Conservation, Regeneration and Restoration of Mediterranean Pines and Their Ecosystems, Proceedings of the International Workshop MEDPINE 3, Bari, Italy, 26-30 September 2009; Options Méditerranéennes: Série A. Séminaires Méditerranéens; n. 75; Leone, V., Lovreglio, R., Eds.; CIHEAM: Bari, Italy, 2007; Volume 3, pp. 33-42.

18. Ganatsas, P.P.; Tsakaldimi, M.N. Effect of light conditions and salinity on germination behaviour and early growth of umbrella pine (Pinus pinea L.) seed. J. Hortic. Sci. Biotechnol. 2007, 82, 605-610. [CrossRef]

19. Takos, I.; Merou, T. Effect of storage conditions and seed treatment on germination of Cedrus deodara Loud. and C. libani A. Rich. Silvae Genet. 2001, 50, 205-207.

20. Vallejo, V.R.; Smanis, A.; Chirino, E.; Fuentes, D.; Valdecantos, A.; Vilagrosa, A. Perspectives in dryland restoration: Approaches for climate change adaptation. New For. 2012, 43, 561-579. [CrossRef]

21. Pery, R.S.M.; Marfà, O.; Serrano, L. The effect of a hydrophilic polymer on plant water status and survival of transplanted pine seedlings. HortTechnology 1995, 5, 141-143.

22. Bravo-Oviedo, A.; Montero, G. Site index in relation to edaphic variables in stone pine (Pinus pinea L.) stands in south west Spain. Ann. For. Sci. 2005, 62, 61-72. [CrossRef]

23. Semerci, A. Fifth year performance of morphologically graded Cedrus libani seedlings in the Central Anatolia Region of Turkey. Turk. J. Agric. For. 2005, 29, 483-491. 
24. Lebanon Ministry of Environment, United Nations Development Programme, Global Environment Facility (MoE-UNDP-GEF). Safeguarding and Restoring Lebanon's Woodland Resources Project. Technical Report: Recommendations for Improving Reforestation Practices in Lebanon Based on Results of Field Trials; Republic of Lebanon, Ministry of Environment: Beirut, Lebanon, 2014; 97p. Available online: http://www.lb.undp.org/content/lebanon/en/home/library/environment_energy/safeguardingand-restoring-lebanons-woodland-resources-technical/ (accessed on 27 May 2015).

25. SAS Institute Inc. Fixed, random, and mixed models. In SAS/STAT ${ }^{\circledR} 9.2$ User's Guide, 2nd ed.; SAS Institute Inc.: Cary, NC, USA, 2009; Available online: https://support.sas.com/documentation/cdl/en/statug/ 63033/HTML/default/viewer.htm\#statug_intromod_a0000000337.htm (accessed on 13 February 2016).

26. SAS Institute Inc. Repeated statement. In $S A S / S T A T^{\circledR} 9.2$ User's Guide, 2nd ed.; SAS Institute Inc.: Cary, NC, USA, 2009. Available online: http:/ / support.sas.com/documentation/cdl/en/statug/63033/HTML/ default/viewer.htm\#statug_mixed_sect019.htm (accessed on 21 August 2014).

27. SAS Institute Inc. Technical Support. Available online: http://support.sas.com/index.html (accessed on 27 May 2015).

28. Querejeta, J.I.; Roldán, A.; Albaladejo, J.; Castillo, V. Soil water availability improved by site preparation in a Pinus halepensis afforestation under semiarid climate. For. Ecol. Manag. 2001, 149, 115-128. [CrossRef]

(c) 2017 by the authors. Licensee MDPI, Basel, Switzerland. This article is an open access article distributed under the terms and conditions of the Creative Commons Attribution (CC BY) license (http:/ / creativecommons.org/licenses/by/4.0/). 